\title{
Commentary
}

\section{Mental health policy and strategic plan}

M.K. Funk ${ }^{7}$ and N.J. Drew ${ }^{7}$

\section{Why have a mental health policy?}

A mental health policy provides a coherent framework for action, based on broad consultation among stakeholders. It serves to identify and promote guiding principles, values and standards for action, thus working to meet population needs for mental health promotion, prevention, treatment, rehabilitation and prevention of premature mortality

The key components that need to be addressed in a mental health policy include human rights; service organization and delivery; human resources; sustainable financing; civil society and advocacy; quality improvement; information systems; and evaluation.

Key strategic interventions for countries include the development and implementation of a multisectoral policy/strategic action plan for mental health in line with the Comprehensive Mental Health Action Plan 2013-20 and the establishment of a common governance structure, appropriate to the national context, to facilitate and monitor implementation of the multisectoral national policy/strategic action plan.

\section{Case for mental health policy and strategic plan $(1,2)$}

A mental health policy is an official statement by a government or health authority that provides the overall strategic direction for mental health by defining the vision, values, principles, and objectives. Such a policy establishes a broad model for action to achieve that vision.

Policies and plans can help to ensure improved access to community-based services and continuity of care for people with mental health conditions; facilitate the development of effective interventions for preventing mental health problems and promoting mental health; ensure cost-effective allocation of resources; prioritize the allocation of resources for mental health; and foster linkages between health and social services and other key sectors, for example the education sector and the criminal justice system.

Mental health policy and strategic plans are important tools for putting into effect the provisions of mental health legislation in the same way as legislation can facilitate the goals of mental health policies and plans [see paper on mental health legislation in this Supplement (3)].

A comprehensive, evidence-based, human rights-oriented policy and strategic plan framework, along with the political will for their implementation, is critical to ensuring that mental health services meet the needs and requirements of people with mental health conditions.

In some countries, mental health issues and actions will be incorporated within the general health, disability or other relevant policies and plans, while in others, depending on the context, a dedicated mental health policy and plan will be developed in addition to the incorporation of mental health issues into other relevant policies and plans (4).
Key components of a mental health policy and plan $(1,2)$

The key components of a mental health policy include a vision statement, clear objectives and areas for action which then get translated into a mental health action plan that defines the strategies, concrete actions, time frames, targets and indicators used to measure progress and outcomes. The priority areas for action form the substance of the policy and plan and will clarify how the country will promote the elements itemized below.

- Human rights: Promoting the rights of people with mental health conditions should be a key feature of mental health policy and provides a clear purpose and justification for change. Specific issues for marginalized or disadvantaged groups need to be considered and addressed, for example mental health issues relating to children and adolescents, older persons, persons with HIV/AIDS, women, children in orphanages, prisoners, ethnic minority groups, refugees, migrants and internally displaced people.

- Service organization and delivery: The 3 major strategies for facilitating the development of an effective network of mental health services are: shifting care away from large psychiatric hospitals, developing communitybased services, and integrating mental health into general health services [see paper in this Supplement on service reorganization (5)]. The policy should assure access to appropriate pharmacological and non-pharma- 
cological interventions for preventing mental disorders and promoting mental health treatment and recovery. Access to non-health-care interventions in other sectors should also be emphasized to promote inclusion, for example welfare rights, employment and livelihoods, and access to justice. It should address how the mental health workforce will be recruited, trained and retained and establish the direction for supervision and support structures and referral pathways for mental health [see paper in this Supplement on human resources (6)]. Information systems are key to improving the effectiveness and efficiency of the mental health services by enabling well-informed decisions to be taken that improve the quality of care. The areas for action should clarify how mental health indicators will be integrated into the general health information system and how this will be implemented [see paper in this Supplement on mental health surveillance and information (7)].

- Strengthening civil society and advocacy: Organizations comprising persons with mental health conditions can benefit the mental health system in many ways, including by strengthening advocacy efforts, improved understanding of human rights, their participation in decision-making processes, and the development of community support groups for people with mental health conditions as well as their families and carers. The policy and plan need to specify how persons with mental health conditions will be engaged.

- Quality improvement: High quality care means that the latest evidencebased interventions are provided, that available resources are used efficiently, and that services remain accountable to those who use them. Actions should highlight how quality improvement will be achieved and measured (developing national standards for mental health, assess- ment and accreditation of facilities, review of mental health competencies of health care staff, etc.).

- Sustainable financing: Different components of the policy will need to be financed, including the service infrastructure, equipment and technology, and the delivery, training and remuneration of the workforce [see paper in this Supplement on investing in mental health (8)].

- Evaluation: Evaluation is central to determining whether the objectives set out in the policy and plan are being realized and for allowing decision-makers to make short- and long-term service and policy-related decision and changes. The policy and plan should specify how and when implementation efforts will be evaluated [see paper in this Supplement on mental health research (9)].

\section{Key recommendations for ministries of health: how to proceed $(1,2)$}

The steps outlined below should be used flexibly, and not in a rigid sequential manner. The process adopted should be based on existing and established processes for policy development within the country (10). See Boxes 1 and 2 for cases studies from Jordan and Qatar.

\section{Establish a multisectoral policy}

Establish or update a multisectoral policy/strategic action plan for mental health in line with international/ regional human rights instruments with targets based on the Comprehensive Mental Health Action Plan 2013-20.

Set up an overarching entity to oversee and draft the policy and plan

Developing a policy and plan should be carried out by a multi-disciplinary group representing different interests in mental health: professionals, policymakers, civil society, persons with mental health conditions and mental health service users, and representatives from other sectors. Ideally this entity will be mandated by, and situated under, the Ministry of Health so as to have buy-in and commitment to follow the process through.

\section{Gather information, consult and negotiate}

To build political will, it is important to strategically use existing information on the mental health situation to advocate for change, to engage civil society in making the case for reform and to consult and negotiate with all stakeholders even before policy development begins (11).

The relevant authority should collect information about the mental health needs of the population (including the most vulnerable and hard-toreach groups) as well as the current mental health system and services. Key mental health issues can be prioritized by reviewing national and international literature and through interaction with key people in other countries.

It is also important to listen to and work with stakeholders, including persons with mental health conditions and their families and carers, as equal partners and develop policy options that blend the different views with evidence derived from national and international experiences.

\section{Define the vision, values, principles, and objectives of the policy}

The substance of the policy may be established through describing the vision, values, principles, and objectives for mental health. The vision usually sets high but realistic expectations for mental health, describing what is desirable for a country, whereas values and principles represent ethical standards and core rules guiding the policy. Objectives should be aimed at improving the health of the population, responding to people's expectations and requirements, and providing financial protection against the cost of ill-health. 
Achieve political approval and endorsement of the policy

Submit the draft policy to the policymaking forum. Prior to its adoption, it may be necessary to conduct lobbying and advocacy. This may involve, for example the joining of forces of different advocates for the reform so as to create a single, unified and strong coalition force; the dissemination of information about the policy through pamphlets and flyers, newspaper articles, radio and television broadcasts; organizing meetings with and sending letters and documents to key parliamentarians and other influential decision-makers, and so on. It is useful to identify and engage persons of influence who may serve as "champions" for the reform. These may include senior officials within the Ministry of Health, parliamentarians, journalists or well-known national personalities. It is also useful at an early stage in the reform process to identify the potential obstacles as well as facilitating factors and strategies to overcome these and to aid the implementation of the new law.

\section{Operationalizing the objectives of the policy}

Draft the mental health action plan providing the details for operationalizing the objectives of the policy by outlining concrete strategies, activities, time frames, and budgets for their attainment.

- Transform the objectives of the mental health policy into areas for action.

- Formulate the core strategies of the mental health plan with respect to each of the areas for action.

- Define clear and explicit targets and indicators for each strategy.

- Define detailed activities that will enable the strategy to be realized.
- Outline the expected outputs of each activity as well as the potential obstacles and delays that could inhibit the realization of the activity.

- Decide on the specific roles and responsibilities for governmental agencies (health, education, employment, social welfare, housing, justice); academic institutions; professional associations; general health and mental health workers; organizations of persons with mental health conditions and family and carer groups; other relevant non-governmental organizations.

- Define a time frame for each strategy, indicating when each strategy will begin and for how long it will function.

- Calculate the costs of each strategy as well as the total costs of the plan for each year, and define how the strategies are going to be financed (e.g. state funding, social insurance, donors, private insurance, out-of-pocket payments).

\section{Box 1 Case study on mental health policy from Jordan}

Jordan's Mental Health Programme was initiated in 2008 in the wake of the influx of refugees from Iraq. In 2009, a national steering committee was established representing a wide range of stakeholders. In addition, over a 2-year period, a wide range of stakeholders from governmental and semi-governmental bodies, universities and affiliated teaching hospitals, the military sector, users associations, nongovernmental organizations, community-based organizations, and media were consulted and involved in drafting the National 10-year Policy which was launched in 2011. The wide consultative process served to get the endorsement of key decision-makers. A 2-year Action Plan on Mental Health was also developed in January 2011.

The policy includes 12 areas of action encompassing: governance; service organization; human resources; finance; information system; prevention and promotion; human rights and legislation; rehabilitation; psychotropic medications; advocacy, research; monitoring, evaluation and quality improvement. A mental health unit was established within the Primary Health Care Directorate at the Ministry of Health to support the governance component of the policy and to facilitate the implementation of the policy and plan. A multidisciplinary National Technical Committee was formed to advise and support the mental health unit.

The main developmental challenges included difficulty in achieving consensus around the priority areas of action, adopting the bio-psychosocial approach, and downsizing mental hospitals. Specific challenges during the implementation of the policy and plan revolved around shortages of human resources due to financial constraints, high turn-over of staff (relocation to other centres, retirement, etc.), work load in primary health care, and resistance from professional groups.

Particularly successful features of the activities implemented under the policy and plan include:

- integrating mental health into primary health care and channelling trained secondary care staff to provide supervision to primary health care staff;

- introducing mental health units to general hospitals;

- adoption of the multidisciplinary, bio-psychosocial approach at the secondary care level;

- the establishment of Our Step Association to support mental health service users and families.

Additional information on mental health reform in Jordan can be seen via the following links: Part 1: http://www.youtube. com/watch?v=m7Xq96eGZCw; Part 2: http://www.youtube.com/watch?v=DaZrDTfZ6KA. 


\section{Box 2 Case study on policy development and implementation in Qatar}

The launch of the Qatar National Vision 2030 in October 2008 and Qatar's National Development Strategy 2011-2016, provided the impetus and momentum for the formulation of Qatar's National Health Strategy 2011-2016. Mental Health Design is one of the 39 projects under the Qatar National Health Strategy. The National Mental Health Committee led the consultation process involving stakeholders from multiple sectors and disciplines. This resulted in the development and launch of the National Mental Health Strategy in December 2013. The process enjoyed support at the highest political level.

The National Mental Health Strategy includes 10 key pledges to deliver an improved comprehensive mental health system in Qatar. These are:

- raise public awareness about mental health and reduce the stigma associated with mental illness;

- make mental health information resources widely available;

- ensure most people can access their treatment in primary care and community settings;

- develop specialist services that meet the differing needs of individuals and groups;

- ensure care is individually tailored and based on treatments that work;

- develop a sustainable, high-quality mental health workforce for Qatar;

- provide a coordinated multisectoral approach to mental health policy development and planning;

- enact a mental health law in Qatar;

- report improvements in patient care using the mental health minimum data set;

- ensure mental health research evidence translates into improvements in clinical practice and patient outcomes. Implementation milestones have been defined and agreed and aligned with the wider National Health Strategy for Qatar. In order to ensure sustainability, governance and resources identified to support implementation are firmly embedded within the National Health Strategy governance structures overseen by the Minister of Health and the Prime Minister, who is the Chair of the Supreme Council for Health.

\section{Lessons learned}

- Political mandate, leadership and commitment to ensure resources are available are vital.

- Strong leadership and support from key stakeholders is important to drive change forward.

- Consultation and communication with all stakeholders is important to actively involve them in making improvements.

- Advance planning is essential.

Additional information can be found on the National Health Strategy website (http://www.nhsq.info/).

- Adjust the time frames of the strategies and activities in accordance with the resources available in different years.

\section{Governance structure}

- Establish a common governance structure, appropriate to the national context, to facilitate and monitor implementation of the multisectoral national policy/strategic action plan.
- Set up an entity/body responsible for defining rules and procedures for operation of public, private and nongovernmental organizations/sectors, delineating the roles and responsibilities for stakeholders. This body should be properly resourced to facilitate and monitor the implementation of the provisions of the national policy/strategic action plan.

\section{Policy and law reform initiatives}

Anticipate and input into other government policy and law reform initiatives in related areas, for example disability, health systems, primary health care, and maternal health, in order to mainstream and integrate the key mental health issues and to ensure that there are no inconsistencies with the mental health policy.

\section{References}

1. Mental health policy, plans and programmes: WHO mental health policy and service guidance package - module 1 (update 2). Geneva: World Health Organization, 2003 (http:// www.who.int/mental_health/policy/services/essentialpackagelvl/en/index.html, accessed 21 April 2015).
2. Improving health systems and services for mental health. Geneva: World Health Organization; 2009 (http://www.who.int/mental_ health/policy/services/mhsystems/en/, accessed 1 April 2015).

3. Funk MK, Bold NJD. Mental health legislation. East Mediterr Health J. 2015; 21(7):527-30. 
4. Leppo K, Ollila E, Peña S, Wismar M, Cook S, eds. Health in all policies: seizing opportunities, implementing policies. Helsinki, Finland: Ministry of Social Affairs and Health; 2013.

5. Saraceno B, Gater R, Rahman A, Saeed K, Eaton C, Ivbijaro G, et al. Reorganization of mental health services: from institutional to integrated community based models of care delivery. East Mediterr Heath J. 2015; 21(7):477-85.

6. Ivbijaro G, Patel V, Chisholm D, Goldberg D, Khoja TAM, Edwards TM. Informing mental health policies and services in the EMR: cost-effective deployment of human resources to deliver integrated community-based care. East Mediterr Heath J. 2015; 21(7):486-92.

7. Gater R, Chisholm D, Dowrick C. Mental health surveillance and information systems. East Mediterr Heath J. 2015; 21(7):512-6.
8. Chisholm D. Investing in mental health. East Mediterr Health J. 2015; 21(7):531-4.

9. Regan M, Gater R, Rahman A, Patel V. Mental health research: developing priorities and promoting its utilization to inform policies and services. East Mediterr Heath J. 2015; 21(7):517-21.

10. Minoletti A, Sepúlveda R, Horvitz-Lennon M. Twenty years of mental health policies in Chile: lessons and challenges. Int J Ment Health. 2012;41(1):21-37.

11. Ollila E. Health in All Policies: from rhetoric to action. Scand J Public Health. 2011 Mar;39(6 Suppl.):11-18. PMID: 20813799. 